\title{
Optimization of Operating Conditions in Forward Osmosis for Osmotic Membrane Bioreactor
}

\author{
Jian-Jun Qin*,1, Maung Htun Oo ${ }^{1}$, Guihe Tao ${ }^{1}$, E.R. Cornelissen ${ }^{2}$, C.J. Ruiken ${ }^{3}$, K.F. de Korte ${ }^{3}$, \\ L.P. Wessels ${ }^{2}$ and Kiran A. Kekre ${ }^{1}$ \\ ${ }^{I}$ The Centre for Advanced Water Technology, PUB Consultants Pte Ltd, 80/82 Toh Guan Road East, \#C4-03, 608575, \\ Singapore \\ ${ }^{2}$ Kiwa Water Research, P.O. Box 1072, 3430 BB Nieuwegein, the Netherlands \\ ${ }^{3}$ Waternet, Spaklerweg 16, 1096 BA, Amsterdam, The Netherlands
}

\begin{abstract}
Objective of this study was to conduct a baseline study of osmotic membrane bioreactor (OMBR) optimization of operating conditions in forward osmosis (FO). Experiments were conducted with an FO pilot system. Tap water was used as the feed and $\mathrm{NaCl}$ and $\mathrm{MgSO}_{4}$ solutions were used as draw solution. Effects of various operating conditions on flux have been investigated. In addition, pure water permeability of the FO membrane was tested. It was observed that the plant operation could be stablized within $1 \mathrm{~h}$. When the membrane selective layer faced to the feed, a flux of $6.3 \mathrm{~lm}^{-2} \mathrm{~h}^{-1}$ (LMH) was achieved at $24 \mathrm{~atm}$ osmotic pressure and $25^{\circ} \mathrm{C}$ and effects of feed velocity and air velocity on flux were not siganificant under the testing conditions due to low external concentration polarization (ECP). However, when the selective layer faced to the draw solution, the flux was enhanced by $64 \%$ due to much reduced internal concentration polarization (ICP), the flux sharply increased with an increase in velocity of the draw solution in the laminar flow pattern range due to a countable effect of dilutive external concentration polarization (DECP) and leveled off after the flow pattern became turbulent. $\mathrm{NaCl}$ performed much higher efficiency than $\mathrm{MgSO}_{4}$ as an osmotic agent due to a greater solute diffusion coefficient of $\mathrm{NaCl}$.
\end{abstract}

Keywords: Draw solution, forward osmosis, osmotic membrane bioreactor, osmotic pressure.

\section{INTRODUCTION}

OMBR is an innovative MBR technique for reclamation of used water, which combines conventional activated sludge process and FO membrane separation with a reverse osmosis (RO) post-treatment $[1,2]$. In this process, the used water is treated by activated sludge process and then pure water is extracted from the sludge through an FO membrane via a natural osmotic pressure gradient between the used water and a draw solution as the driving force instead of a hydraulic pump in a conventional ultrafiltration/microfiltration MBR. Then, a conventional RO with energy recovery device is used as a post-treatment of the FO permeate diluted solution to produce high quality water and simultaneously to recover the concentrated salt solution as the draw solution which is recycled in OMBR process. The brilliance of the OMBR technology is that we get nature to work for us. OMBR has a potential to enhance water quality and reduce operating cost. The key for this novel technology to be most cost effective is to achieve a high water flux in the $\mathrm{FO}$ process.

FO has been extensively investigated in various water treatment/engineering applications [3] such as treating industrial wastewater [4]; being evaluated for reclaiming

*Address correspondence to this author at the Centre for Advanced Water Technology, PUB Consultants Pte Ltd, 80/82 TOH Guan Road East, \#C403, Singapore 608575; Tel: +65-63262914; Fax: +65-63262929;

E-mail: QIN_Jianjun@pub.gov.sg wastewater for potable reuse in life support systems [5]; and desalinating seawater [6,7]. In recent years, FO has been increasingly attractive for RO fouling control as it is a highly efficient and environmentally friendly technique [8-10]. Seldom studies on OMBR have been published as this technology is at early stage of development. Objective of this research was to conduct a baseline study on OMBR optimization of operating conditions in FO process.

\section{EXPERIMENTAL MATERIALS AND METHODS}

The pilot unit with membrane area of $0.1 \mathrm{~m}^{2}$ from Hydrationtech used for the FO experiments is shown in Fig. (1). The flow channels at both feed side and draw solution side were originally same. A spacer was required to add into one side to support the membrane. The spacer was chosen to add into the draw solution side because the draw solution would be always clean while the activated sludge feed in the next study after this baseline study would easily block the feed channel if the spacer be at the feed side. The crosssection area of flow channels at feed side and draw solution side (with a spacer) of the flat sheet membrane are $7 \times 10^{-4} \mathrm{~m}^{2}$ and $3.75 \times 10^{-4} \mathrm{~m}^{2}$, respectively. Therefore, the velocity of a fluid in a channel can be calculated when its flow rate is measured [11].

Tap water with average conductivity of $170 \mu \mathrm{S} / \mathrm{cm}$ was used as the feed in a single pass mode. The feed characteristics are shown in Table 1. Concentration of the draw solution was maintained during testing via automatically 


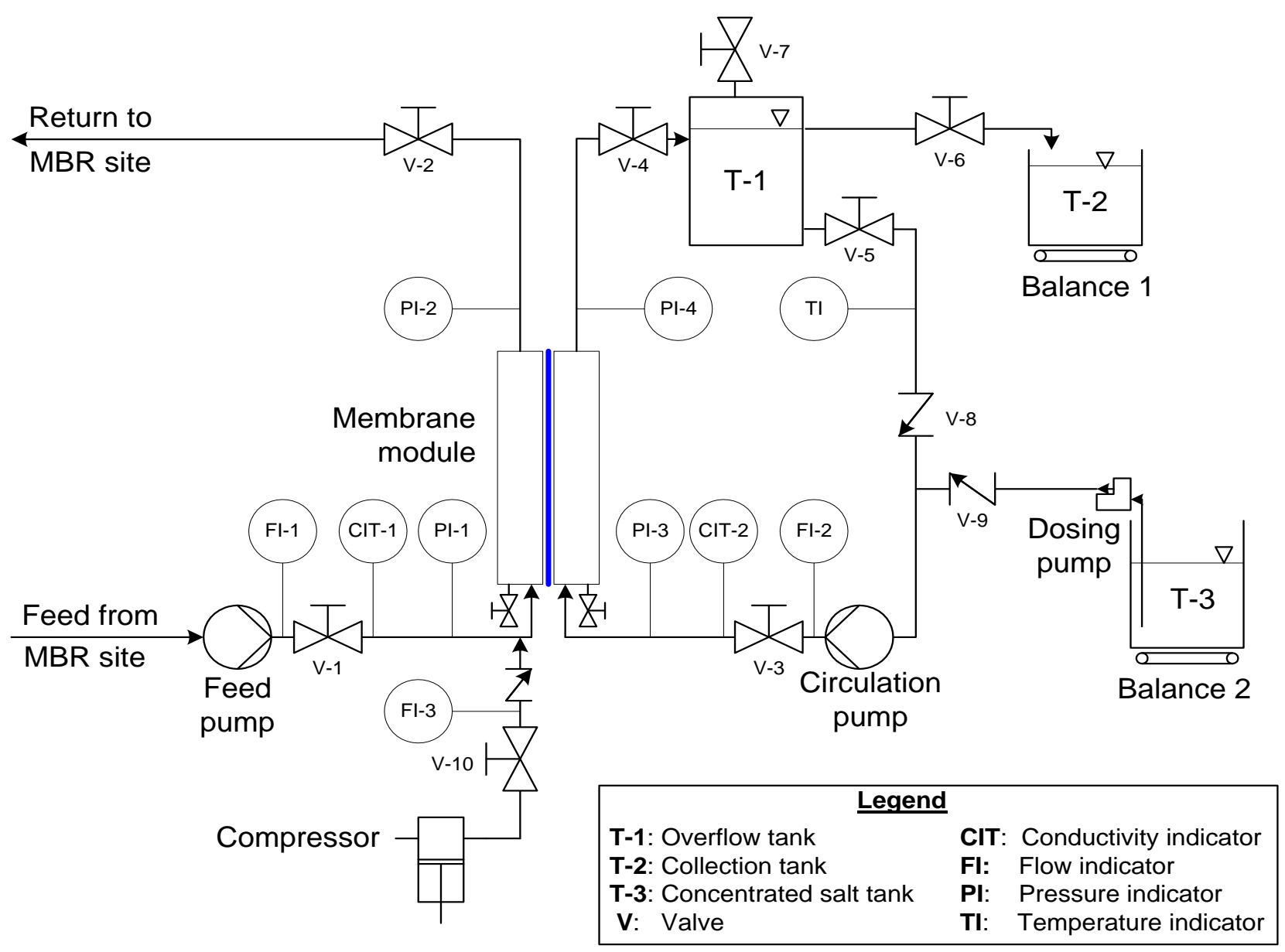

Fig. (1). Schematic of FO pilot unit.

Table 1. Characteristics of the Feed

\begin{tabular}{|c|c|c|c|c|c|c|c|c|c|c|c|c|c|c|c|c|}
\hline Parameter & NH4 & B & $\mathrm{Ca}$ & $\mathrm{Cl}$ & $\mathbf{F}$ & $\mathbf{F e}$ & Mg & $\mathbf{N i}$ & NO3 & pH & PO4 & $\mathrm{SiO2}$ & $\mathbf{N a}$ & SO4 & TDS & TOC \\
\hline
\end{tabular}

Remarks: Units of value are mg/L except for $\mathrm{pH}$; ND- Not detected.

controlling a constant conductivity of the draw solution in the re-circulation loop interlocked with dosage of a concentrated salt solution. Unless specified elsewhere, experiments were conducted with the membrane orientation of active layer faced to the feed, the feed and draw solution flow rates were $2.4 \mathrm{gpm}(545 \mathrm{l} / \mathrm{h})$ and $2.5 \mathrm{gpm}(568 \mathrm{l} / \mathrm{h})$, respectively while the draw solution was $0.5 \mathrm{M} \mathrm{NaCl}$.

The uniqueness of this system design is that a dosing system with automatic controls was introduced to keep a constant concentration of draw solution during the testing. There was no such a dosing facility in previous studies and concentration of draw solution decreased with the time during any testing. Subsequently, the concentration of draw solution was also a variable in their experiments although investigation on the effect of another parameter was desired. Balance 1 and 2 are to record the weight gain in draw solution loop and the weight loss from concentrated salt tank. Air compressor is provided in the feed loop to increase the turbulence in the feed channel for minimization of external concentration polarization (ECP). Data-logger is installed at the control panel of testing unit to continuously monitor and record CIT-1, CIT-2, PI-1, PI-2, PI-3, PI-4, two balances. Fig. (2) shows a photo of the FO pilot unit.

In practice, the temperature-corrected water flux was obtained from experiments and calculated by equation 1 [12].

$\mathrm{J}=1.03^{(298-\mathrm{T})} \mathrm{Q}_{\mathrm{p}} / \mathrm{A}_{\mathrm{m}}$

Where: $J=$ temperature-corrected water flux, $\left(1 / \mathrm{m}^{2} / \mathrm{h}\right.$ at 25 $\left.{ }^{\circ} \mathrm{C}\right) ; \mathrm{Q}_{\mathrm{p}}=$ water flow rate, $(\mathrm{l} / \mathrm{h}) ; \mathrm{A}_{\mathrm{m}}=$ effective membrane area, $\left(\mathrm{m}^{2}\right)$ T-temperature $(\mathrm{k})$.

\section{RESULTS AND DISCUSSION}

\section{Determination of the Steady State}

Fig. (3) shows the net gain of FO permeate as a function of time and each of the tests was conducted under fixed experiment conditions. The results indicate that an experiment could reach a steady state within $1 \mathrm{~h}$. Therefore, all experiments in this study were designed to conduct over 1 


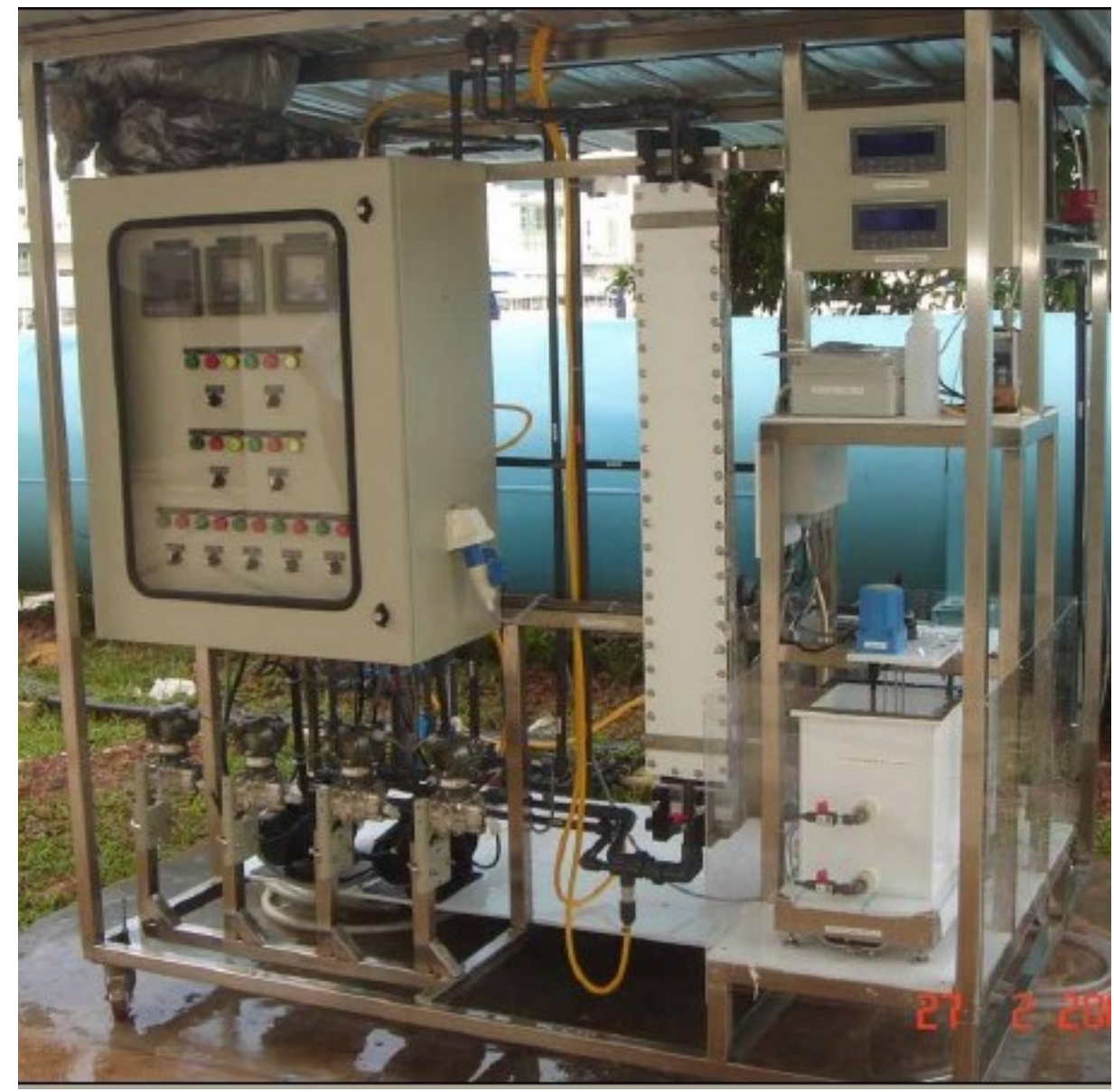

Fig. (2). Photo of the FO pilot unit.

$\mathrm{h}$ for each particular test. In addition, the net gain increased for Test 1 while it decreased with the time for Test 2 before leveled off. These could be attributed to the facts that the feed was pre-filled in the system while the draw solution was filled just before the experiment started in Test 1, resulting in an increase in driving force with the time before stabilization, however, the situation was opposite in Test 2, resulting in a decrease in driving force with the time before stabilization.

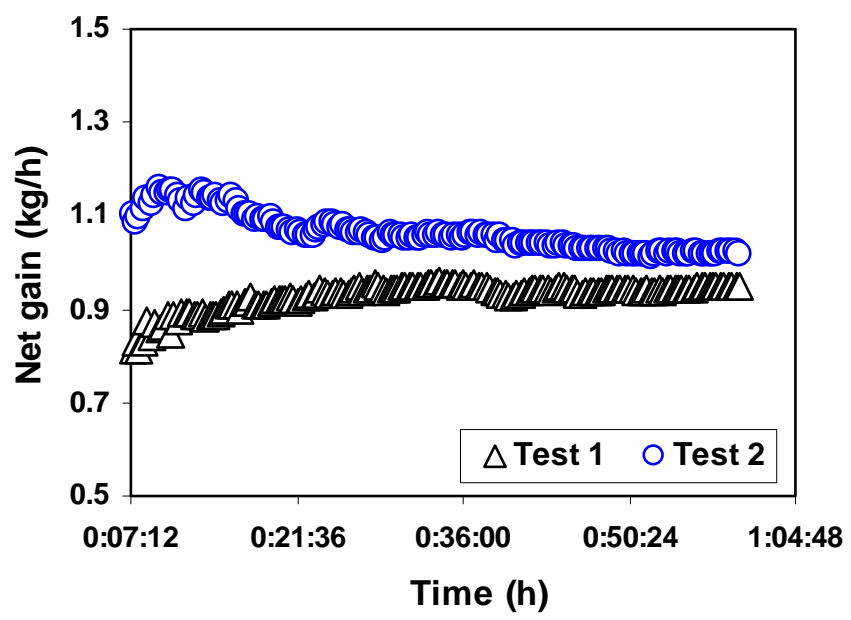

Fig. (3). Net gain of the permeate vs. time.

\section{Effect of Feed Velocity on Water Flux}

Fig. (4) shows that no significant effect of feed velocity on water flux was observed. This could be attributed to a low salt concentration of the feed (tap water), resulting in a small concentrative external concentration polarization (CECP) contribution to the flux [13].

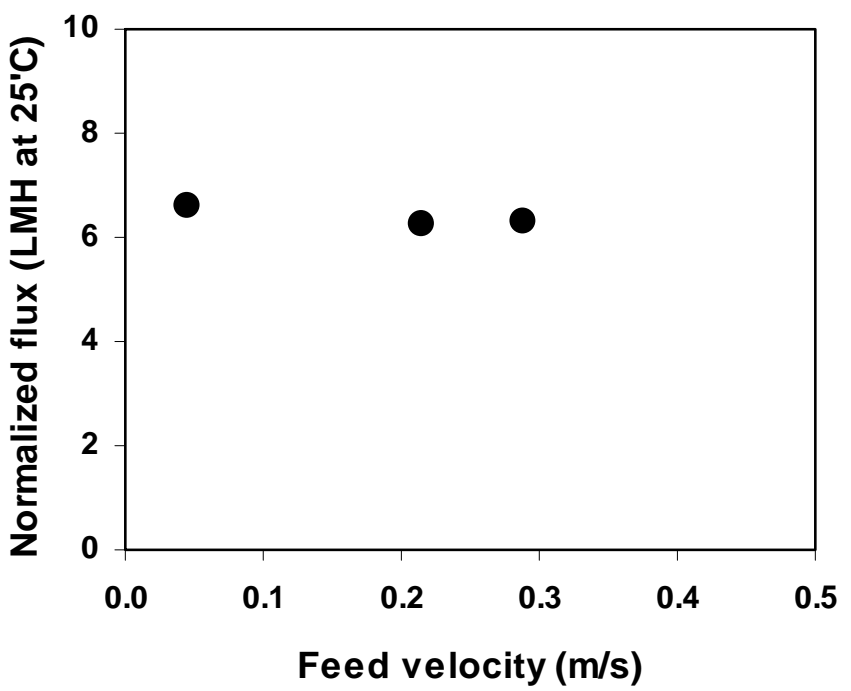

Fig. (4). Effect of feed velocity on flux. 


\section{Effect of Air Velocity at Feed Side on Water Flux}

When the membrane selective layer faced to the feed, air was introduced in the feed side to simulate the OMBR situation that a minimum air scouring on the membrane surface would be required at the feed side with activated sludge to prevent membrane fouling or to remain flux. Fig. (5) shows the effect of air velocity at feed side on water flux and no significant difference is observed even if the experiments were conducted at a low feed flow rate of 114 $\mathrm{L} / \mathrm{h}$ (usually $545 \mathrm{~L} / \mathrm{h}$ ). This could be also attributed to a low salt concentration of the feed (tap water), resulting in a small CECP contribution to the flux with the turbulence of air flow.

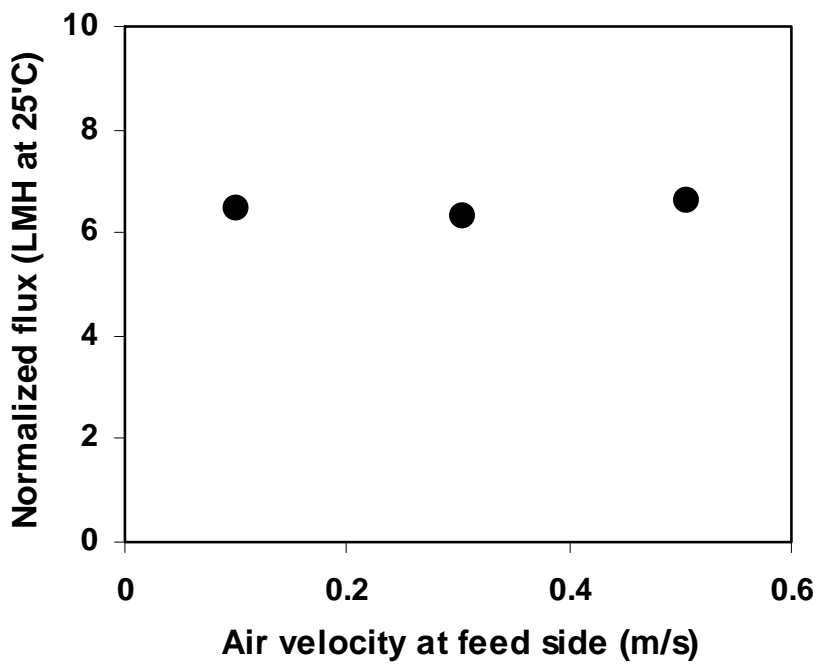

Fig. (5). Effect of air velocity on flux.

\section{Effects of Different Draw Solutions and Concentrations on Water Flux}

Fig. (6) shows the experimental water flux in FO mode as a function of the calculated osmotic pressure difference between the draw solution and the feed corresponding to $\mathrm{NaCl}$ and $\mathrm{MgSO}_{4}$ draw solution concentration since osmotic pressure difference is the driving force in FO operation. It shows that the flux almost linearly increased with the osmotic pressure difference in the range of 24-93 atm for $\mathrm{NaCl}(0.5-1.8 \mathrm{M})$. However, for $\mathrm{MgSO}_{4}(0.22-0.75 \mathrm{M})$, the flux increased with the apparent driving force in the low range of 6-19 atm and then leveled off. Also it can be seen that $\mathrm{NaCl}$ draw solution performed a much higher water flux than $\mathrm{MgSO}_{4}$ under the same osmotic pressure difference. The results indicate that water flux will not only depend on the concentration of draw solution but also the type of draw solution [3]. This could be due to a greater solute diffusion coefficient of $\mathrm{NaCl}$ than $\mathrm{MgSO}_{4}$ [14], resulting in a higher efficiency of $\mathrm{NaCl}$ than $\mathrm{MgSO}_{4}$ as an osmotic agent. Moreover, $\mathrm{MgSO}_{4}$ efficiency was obviously impressed when the calculated osmotic pressure difference was over $19 \mathrm{~atm}$ because osmotic coefficient of $\mathrm{MgSO}_{4}$ decreases significantly with an increase in concentration when $\mathrm{MgSO}_{4}$ concentration was higher than $0.75 \mathrm{M}[15]$.

Pure water flux of the FO membrane vs. operating pressure was measured in RO mode and also plotted in Fig.
(6). Pure water permeability coefficient of the FO membrane, A, was obtained at $0.67 \mathrm{~L} \mathrm{~m}^{2-} \mathrm{h}^{-1} \mathrm{~atm}^{-1}$. Moreover, it can be seen that the actual water flux in FO mode was much lower than the ideal pure water flux under the same driving force. This could be due to the coupled effect of CECP and dilutive internal concentration polarization (DICP), resulting in the effective driving force for FO was much lower than the calculated osmotic pressure difference [13].

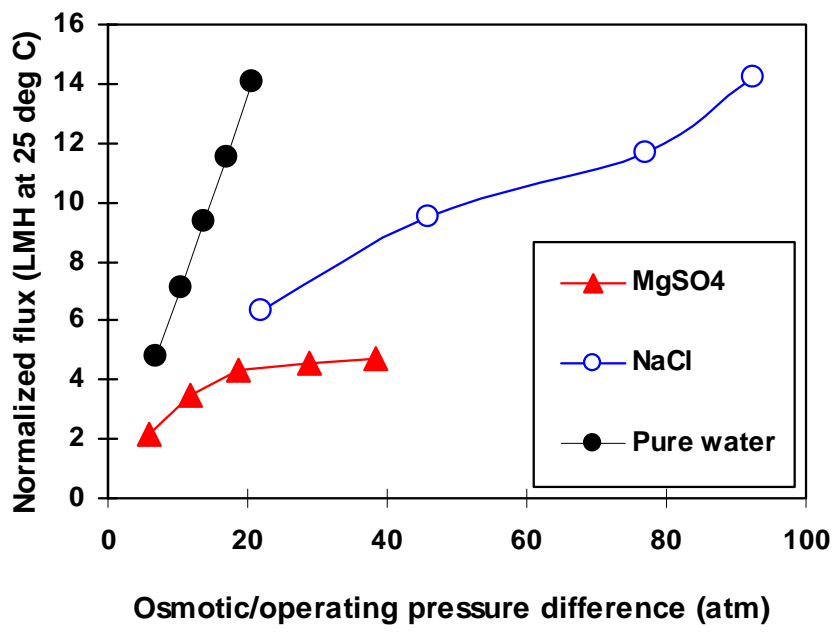

Fig. (6). Comparison of actual flux for different draw solutions with ideal pure water flux.

\section{Effect of Draw Solution Velocity on Water Flux}

Experiments were conducted with the membrane orientation of active layer faced to the draw solution of 0.5 $\mathrm{M} \mathrm{NaCl}$. Fig. (7) shows the effect of draw solution velocity on water flux. It can be seen that the flux sharply increases with an increase in the draw solution velocity at low velocity (corresponding to the laminar flow pattern) and levels off when the flow pattern becomes turbulent. This could be attributed to a high salt concentration of the draw solution, resulting in a countable contribution of dilutive external concentration polarization (DECP) to the flux. The hypothesis will be supported by the modeling analysis in future work.

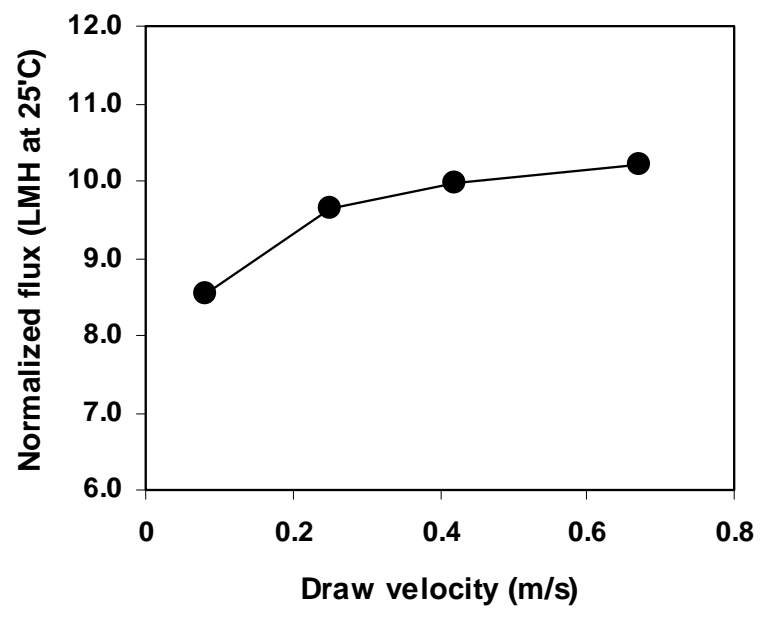

Fig. (7). Effect of draw velocity on flux. 
In addition, the water flux reached $10.3 \mathrm{LMH}$ at $0.4 \mathrm{~m} / \mathrm{s}$, which was enhanced by $64 \%$ compared to $6.3 \mathrm{LMH}$ when the active layer faced to the feed. This could be attributed to the much less concentrative internal concentration polarization (CICP) at the feed side comparing dilutive internal concentration polarization (DICP) at the draw solution side when the membrane selective layer faced to the feed [16].

\section{FUTURE WORK}

Intensive investigations of OMBR with the activated sludge from a DEMO MBR Plant and the comparison with a conventional MBR are in progress. Other draw solutions with an appropriate post-treatment other than salt solutions with RO post-treatment will be investigated in future to make the OMBR process more cost effective.

\section{CONCLUSIONS}

The conclusions from the study may be summarized as follows:

1) Water fluxes of $6.3 \mathrm{LMH}$ and $10.3 \mathrm{LMH}$ were achieved with osmotic pressure of $24 \mathrm{~atm}(0.5 \mathrm{M}$ $\mathrm{NaCl})$ at $25^{\circ} \mathrm{C}$ when the active layer faced to the feed and the draw solution, respectively.

2) Effects of feed velocity and air velocity at the feed side on water flux were not siganificant under the testing conditions when the active layer faced to the feed due to low ECP. However, there was a certain influence of draw velocity on water flux when the active layer faced to the draw solution due to the effect of DECP.

3) Huge reduction of water flux compared to the ideal pure water flux due to the coupled effects of CECP and DICP.

4) $\mathrm{NaCl}$ was a much higher efficient osmotic agent than $\mathrm{MgSO}_{4}$ due to a greater solute diffusion coefficient of $\mathrm{NaCl}$.

Selection of a high performance FO membrane is a limitation in this study as a thinner FO membrane would reduce DICP and achieve higher flux. For a proper choice of some major parameters, it is recommended that the air velocity can be at $0.1 \mathrm{~m} / \mathrm{s}$ when the membrane selective layer faces to the feed while velocity of the draw solution can be $0.3 \mathrm{~m} / \mathrm{s}$ when the membrane selective layer faces to the draw solution.

\section{NOMENCLATURE}

$\begin{array}{lll}J_{w} & \begin{array}{l}\text { water flux } \\ \text { temperature-corrected } \\ \text { water flux at } 25^{\circ} \mathrm{C}\end{array} & {\left[\mathrm{L} \mathrm{m}^{2-} \mathrm{h}^{-1}\right]} \\ & {\left[\mathrm{L} \mathrm{m}^{2-} \mathrm{h}^{-1}\right]} \\ \text { A } & \begin{array}{l}\text { water permeability } \\ \text { constant of the FO } \\ \text { membrane }\end{array} & {\left[\mathrm{L} \mathrm{m}^{2-} \mathrm{h}^{-1} \mathrm{~atm}^{-1}\right]} \\ & \begin{array}{l}\text { effective membrane area } \\ \mathrm{A}_{\mathrm{m}}\end{array} & {\left[\mathrm{m}^{2}\right]} \\ \sigma & \begin{array}{l}\text { reflection coefficient } \\ \text { the osmotic pressure }\end{array} & {[-]} \\ \pi & \text { the osmotic pressure } & {[\mathrm{atm}]} \\ \Delta \pi & \text { differential } & \end{array}$

$\begin{array}{llll}\mathrm{Q}_{\mathrm{p}} & \text { water flow rate } & & {\left[\mathrm{L} \mathrm{h}^{-1}\right]} \\ \mathrm{c} & \begin{array}{l}\text { concentration of } \\ \text { solution } \\ \end{array} & \text { number of ions } & {[\mathrm{M}]} \\ \mathrm{n} & & {[-]} \\ \mathrm{R} & \text { gas constant }=0.082057 & {\left[\mathrm{~L} \cdot \mathrm{atm} \cdot \mathrm{K}^{-1} \cdot \mathrm{mol}^{-1}\right]} \\ \mathrm{T} & \text { temperature } & {[\mathrm{K}]} \\ \psi & \text { osmotic coefficient } & {[-]}\end{array}$

\section{ACKNOWLEDGEMENTS}

The authors acknowledge the support of both the Innovation for Environmental Sustainability Fund of the National Environment Agency, Singapore (project number NEA/EP/PDD/05-13097) and the Senter Novem of the Dutch Ministry of Economic Affairs (project number ISO54040). The authors like to thank Winson Lay Chee Loong, Cheun Hong Lew and Chee Meng Ang for their support in the study.

\section{REFERENCES}

[1] E.R. Cornelissen, D. Harmsen, K.F. de Korte, C.J. Ruiken, J. J. Qin, H. Oo, and L.P. Wessels, "Membrane fouling and process performance of forward osmosis membranes on activated sludge", J. Membr. Sci., vol. 319, pp.158-168, 2008.

[2] A. Achilli, T.Y. Cath, E.A. Marchand, and A.E. Childress, "The novel osmotic membrane bioreactor for wastewater treatment", In: Proc. of the 81st Annual Water Environment Federation Technical Exhibition and Conference, October 18-22, Chicago, USA, 2008.

[3] T.Y. Cath, A. E. Childress, and M. Elimelech, "Forward osmosis: principles, applications, and recent developments", J. Membr. Sci., vol. 281, pp.70-87, 2006.

[4] R. W. Holloway, A. E. Childress, K. E. Dennett, and T.Y. Cath, "Forward osmosis for concentration of anaerobic digester centrate", Water Res., vol. 41, pp. 4005-4014, 2007.

[5] T.Y. Cath, S. Gormly, E.G. Beaudry, V.D. Adams, and A. E. Childress, "Membrane contactor processes for wastewater reclamation in space. I: direct osmotic concentration as pretreatment for reverse osmosis", J. Membr. Sci., vol. 257, pp. 8598, 2005.

[6] R.E. Kravath, and J.A. Davis, "Desalination of seawater by direct osmosis", Desalination, vol.16, pp.151-155, 1975.

[7] J.R. McCutcheon, R.L. McGinnis, and M. Elimelech, "A novel ammonia-carbon dioxide forward (direct) osmosis desalination process", Desalination, vol.174, pp.1-11, 2005.

[8] B. Liberman, and I. Liberman, "RO membrane cleaning - replacing membrane CIP by direct osmosis cleaning", Desalination Water Reuse, vol. 15, pp. 28-32, 2005.

[9] I. Liberman, "RO membrane cleaning method", United States Patent Application, 20070181497, 2007.

[10] J. J. Qin, B. Liberman, and K. A. Kekre, "Review: direct osmosis for reverse osmosis fouling control: principles, applications and recent developments", Open Chem. Eng. J., vol.3, pp.8-16, 2009.

[11] K.W. Chau, "Transverse mixing coefficient measurements in an open rectangular channel", Adv. Environ. Res., vol. 4, pp. 287-294, 2000.

[12] M. Elimelech, "Membrane technology in water and wastewater treatment", Lecture notes at National University of Singapore, 4-6 July 2001.

[13] J.R. McCutcheon, and M. Elimelech, "Influence of concentrative and dilutive internal concentration polarization on flux behaviour in forward osmosis", J. Membr. Sci., vol. 284, pp. 237-247, 2006.

[14] V. M. M. Lobo, "Mutual diffusion coefficients in aqueous electrolyte solutions", Pure Appl. Chem., vol. 65, pp. 2613-2640, 1993.

[15] S.P. Tan, X. Ji, H. Adidharma, and M. Radosz, "Statistical associating fluid theory coupled with restrictive primitive model 
extended to bivalent ions. SAFT2: 1. single salt + water solutions", J. Phys. Chem. B., vol.110, pp.16694-16699, 2006.

[16] H. Y. Ng, W. Tang, and W. S. Wong, "Performance of forward (direct) osmosis process: membrane structure and transport phenomenon", Environ. Sci. Technol., vol. 40, pp. 2408-2413, 2006

Received: March 09, 2009

Revised: May 27, 2009

Accepted: May 28, 2009

(C) Qin et al.; Licensee Bentham Open.

This is an open access article licensed under the terms of the Creative Commons Attribution Non-Commercial License (http://creativecommons.org/licenses/by-nc/3.0/) which permits unrestricted, non-commercial use, distribution and reproduction in any medium, provided the work is properly cited. 